\title{
Formulation and Optimization of Orally Disintegrating Tablets of Sumatriptan Succinate
}

\author{
Ravi Sheshala, ${ }^{a, b}$ Nurzalina Khan, ${ }^{a}$ and Yusrida Darwis* ${ }^{*} a$ \\ ${ }^{a}$ School of Pharmaceutical Sciences, Universiti Sains Malaysia; 11800 Penang, Malaysia: and ${ }^{b}$ School of Pharmacy and \\ Health Sciences, International Medical University; Bukit Jalil, 57000 Kuala Lumpur, Malaysia. \\ Received December 17, 2010; accepted May 6, 2011; published online May 12, 2011
}

\begin{abstract}
The aims of the present research were to mask the intensely bitter taste of sumatriptan succinate and to formulate orally disintegrating tablets (ODTs) of the taste masked drug. Taste masking was performed by coating sumatriptan succinate with Eudragit EPO using spray drying technique. The resultant microspheres were evaluated for thermal analysis, yield, particle size, entrapment efficiency and in vitro taste masking. The tablets were formulated by mixing the taste masked microspheres with different types and concentrations of superdisintegrants and compressed using direct compression method followed by sublimation technique. The prepared tablets were evaluated for weight variation, thickness, hardness, friability, drug content, water content, in vitro disintegration time and in vitro drug release. All the tablet formulations disintegrated in vitro within $37-410 \mathrm{~s}$. The optimized formulation containing $\mathbf{5 \%}$ Kollidon CL-SF released more than $90 \%$ of the drug within $15 \mathrm{~min}$ and the release was comparable to that of commercial product (Suminat $\left.{ }^{\circledR}\right)$. In human volunteers, the optimized formulation was found to have a pleasant taste and mouth feel and disintegrated in the oral cavity within $41 \mathrm{~s}$. The optimized formulation was found to be stable and bioequivalent with Suminat ${ }^{\circledR}$.
\end{abstract}

Key words sumatriptan succinate; orally disintegrating tablet; superdisintegrant; sublimation; disintegration time; in vivo study

Migraine is a common disorder characterized by a unilateral headache that is often associated with nausea, vomiting, gastrointestinal disturbance and extreme sensitivity to light and sound. ${ }^{1,2)}$ Sumatriptan succinate is the first member of a new class of antimigraine compounds that act as a specific and selective 5-hydroxytryptamine-1 receptor agonist. Consequently, it is a novel and effective acute treatment for migraine via the oral route in the tablet form, parenteral route as a subcutaneous injection and nasal route as nasal spray. Injected sumatriptan works the fastest of all the dosage forms available and is the most effective but it is inconvenient due to pain at the injection site and it also requires a trained person to administer the dose. The nasal spray bypasses the stomach, gets absorbed more quickly than the oral form and relieves the pain within 15 min after administration. However, it is less effective when the patient has nasal congestion from cold or allergy and it also leaves a bad after taste. The oral administration in the form of conventional tablet is a convenient method but in some instances, such as during travel where the patients have little or no access to water, administration of drug is not feasible and carries a risk of choking. Moreover, a substantial proportion of patients suffer from severe nausea or vomiting during their migraine attack. In such condition, even if the patient has access to water, ingestion of conventional tablet could lead to vomiting and expulsion of a portion or the entire dose administered which leads to treatment failure. ${ }^{4)}$ All these factors limit the utility of conventional tablets. Thus, the orally disintegrating tablet (ODT) delivery system for sumatriptan succinate may be a viable alternative for self-administration, whereby these limitations could be overcome.

Sumatriptan succinate is a highly water soluble and intensely bitter drug. If it is incorporated directly into ODTs, the main objective behind formulation of such a dosage form will definitely be futile due to the bitterness of the drug. Therefore, its high solubility in water and bitter taste makes sumatriptan succinate a challenging drug candidate for ODT drug delivery system.

Sumatriptan succinate is not available in the dosage form of ODT in the market world over. To the best of our knowledge, there is only one published article on the formulation of sumatriptan succinate ODTs ${ }^{5}$ but the researchers have not performed taste masking experiments for the drug which is a prime parameter to improve the patient compliance and the quality of treatment. Thus, in the present study, an attempt has been made to mask the intensely bitter taste of sumatrip$\tan$ succinate and to formulate ODTs with a pleasant taste and mouth feel in the oral cavity so as to prepare a "patientfriendly dosage form." The in vivo performance of the optimized formulation was also demonstrated using rabbits as an animal model.

\section{Experimental}

Materials Sumatriptan succinate was purchased from Nosch Labs (Hyderabad, India). Microcrystalline cellulose (Avicel PH 112) and croscarmellose sodium (CCS) were obtained as gift samples from FMC Biopolymer (Newark, U.S.A.). Crospovidone (Polyplasdone XL and XL-10) was provided as gift samples from ISP Technologies (New Jersey, U.S.A.). Sodium starch glycolate (SSG) was provided as a gift sample from DMV International (New Jersey, U.S.A.). Kollidon CL and CL-SF were obtained as gift samples from BASF (Ludwigshafen, Germany). Low substituted hydroxypropyl cellulose (L-HPC, LH11) was obtained as a gift sample from ShinEtsu (New York, U.S.A.). Calcium silicate was obtained as a gift sample from Huber Chem (Mumbai, India). Ammonium bicarbonate was purchased from Sigma-Aldrich (St. Louis, U.S.A.). Aspartame and pineapple flavor were provided as gift samples from Nutrasweet (Chicago, U.S.A.). Magnesium stearate was purchased from Micro Orgo Chem (Mumbai, India). Aerosil was purchased from Cabot Corp. (Boston, U.S.A.). Ammonium acetate was purchased from Nacalai Tesque (Kyoto, Japan). tert-Butyl methyl ether (TBME) was purchased from Acros Organics (New Jersey, U.S.A.). Dichloromethane (DCM) was purchased from R\&M Chemicals (Essex, U.K.). Ethyl acetate (EA) was purchased from Lab Scan (Bangkok, Thailand). HPLC grade of methanol and acetonitrile were purchased from J.T.Baker (Phillipsburg, U.S.A.).

Preparation of Spray Dried Microspheres Sumatriptan succinate taste masked microspheres were prepared by spray drying technique at drug : polymer : organic solvent ratios of $1: 0.5: 50,1: 0.75: 50$ and $1: 1: 50$. The polymer, Eudragit EPO was dissolved in ethyl acetate and then drug was added to prepare a suspension. The prepared suspension was stirred 
using Heidolph stirrer at $500 \mathrm{rpm}$ to maintain uniformity and sprayed through a nozzle (diameter of $0.7 \mathrm{~mm}$ ) using a spray dryer (Lab Plant SD04, Huddersfield, U.K.). The spray dryer was operated under the following conditions: inlet and outlet temperatures of 80 and $55-61{ }^{\circ} \mathrm{C}$, respectively, blower setting at $70 \%$ and peristaltic pump setting at $30 \%$. The resultant taste masked microspheres stored in a tightly closed container over silica gel until further use.

Evaluation of Spray Dried Microspheres. In Vitro Taste Masking The study was conducted in accordance to the method adopted from Shukla et al. ${ }^{6)}$ The required amount of spray dried microspheres equivalent to $70 \mathrm{mg}$ sumatriptan succinate was placed in a $25 \mathrm{ml}$ beaker. A volume of $5 \mathrm{ml}$ phosphate buffer solution pH 6.8 (United States Pharmacopeia (USP)) was added and the mixture was allowed to stand for $60 \mathrm{~s}$. A $5 \mathrm{ml}$ volume of phosphate buffer $\mathrm{pH} 6.8$ was used to mimic the salivary fluid volume and $\mathrm{pH}$. After the specified time, the suspension was filtered through $0.45 \mu \mathrm{m}$ nylon membrane filter. The filtrate was analyzed for drug content using UV/Visible spectrophotometer (Hitachi, Japan) at $227 \mathrm{~nm}$. The experiment was run in triplicate.

Thermal Analysis Differential Scanning Calorimetry (DSC) (Perkin Elmer, Pyris 6 DSC, California, U.S.A.) was used to evaluate the compatibility between sumatriptan succinate and Eudragit EPO. The DSC experiments were performed on plain drug, Eudragit EPO and spray dried drug loaded microspheres. Accurately weighed samples $(5-7 \mathrm{mg})$ were sealed in flat bottom aluminium pans and thermograms were recorded at a constant rate of $10^{\circ} \mathrm{C} / \mathrm{min}$ over a temperature range of $30-300^{\circ} \mathrm{C}$. Inert atmosphere was provided by purging helium gas at a flow rate of $20 \mathrm{ml} / \mathrm{min}$. An empty pan sealed in the same way as the sample was used as a reference. The experiment was run in triplicate.

Particle Size The analysis was performed using a Mastersizer S (Malvern Instruments, U.K.) fitted with MS1 small volume sample dispersion unit connected to a dispersion unit controller. The spray dried microspheres were dispersed in water and sonicated for 2 min using bath sonicator (Branson 5200, Branson Ultrasonics, Danbury, U.S.A.) to prevent aggregation before measuring particle size. Samples were analyzed in triplicate.

Drug Entrapment Efficiency, Loading and Yield The entrapment efficiency and drug loading in microspheres was estimated by dissolving $50 \mathrm{mg}$ of spray dried powder in methanol and further diluted with $0.01 \mathrm{~N} \mathrm{HCl}$. The samples were analyzed using UV/Visible spectrophotometer (Hitachi, Japan) at a wavelength of $227 \mathrm{~nm}$. Entrapment efficiency, drug loading and yield were calculated using the following equations

$$
\begin{aligned}
& \text { drug entrapment efficiency }(\%)=\frac{\text { weight of drug in microspheres }}{\text { weight of drug fed initially }} \times 100 \% \\
& \text { drug loading }(\%)=\frac{\text { weight of drug in microspheres }}{\text { weight of microspheres }} \times 100 \% \\
& \text { yield }(\%)=\frac{\text { weight of microspheres }}{\text { weight of drug and Eudragit EPO }} \times 100 \%
\end{aligned}
$$

Preparation of Tablets The ODTs were prepared by direct compression method. The ODTs containing uncoated sumatriptan succinate (formulation F0) were used as control. The taste masked sumatriptan succinate ODTs (formulation F1 to F31) consisted of the spray dried microspheres containing drug and polymer at a ratio of $1: 1(150 \mathrm{mg}$ equivalent to $70 \mathrm{mg}$ of sumatriptan succinate), Avicel PH 112, superdisintegrant, pore forming agent (calcium silicate), subliming agent, aspartame and pineapple flavor (Table 1). The ingredients were passed through $0.8 \mathrm{~mm}$ sieve and mixed intimately by geometric dilution. The obtained blend was lubricated with magnesium stearate and Aerosil was added as a glidant before compression. The blend was compressed on a single station tableting machine (Manesty, Liverpool, U.K.) using $10 \mathrm{~mm}$ concave punches. The tablets weight was kept at $320 \mathrm{mg}$ and hardness was maintained in the range of $2-3 \mathrm{~kg}$. The tablets (F5 and F8 to F31) were kept in an oven at $40^{\circ} \mathrm{C}(15-21 \mathrm{~h})$ until a constant weight was obtained to facilitate sublimation of subliming agent (ammonium bicarbonate).

Evaluation of Tablets. Physical Properties of Tablets Twenty tablets were selected randomly to determine the tablets weight variation. Tablets were weighed individually using an electronic balance (Denver instruments, U.S.A.) and compared with an average weight. Thickness of the tablets was assessed using digital caliper (Neiko, U.S.A.). Hardness of the tablets was determined using a Vanguard hardness tester in the units of $\mathrm{kg}$ (YD-2 model, Vanguard, U.S.A.). The mean hardness of 10 tablets was calculated and reported. Twenty preweighed tablets were rotated at $25 \mathrm{rpm}$ for $4 \mathrm{~min}$ in friability test apparatus (CS-1 tablet friability tester, U.S.A.) to measure the friability of the tablets. The tablets were then dedusted, reweighed and loss in weight (\%) was calculated. The test was run once for each formulation.

Drug Content Ten tablets from each formulation were randomly selected and pulverized to a fine powder. A portion of powder equivalent to a single dose $(70 \mathrm{mg})$ of sumatriptan succinate was accurately weighed and assayed for the drug content using UV/Visible spectrophotometer (Hitachi, Japan) at a wavelength of $227 \mathrm{~nm}$. The mean percent drug content was calculated as an average of three determinations.

Water Content The tablets which produced in vitro disintegration time of less than $60 \mathrm{~s}$ were evaluated for water content using Karl Fischer titrator (Metrohm 703 Ti Stand, Germany). The tablet was pulverized, inserted in the titration vessel containing dried methanol (Karl Fischer grade) and titrated with Hydranal Composite 5 reagent (Riedel-de-Häen, Germany) after a stirring time of $3 \mathrm{~min}$. The samples were analyzed in triplicate.

In Vitro Disintegration Time The test was carried out using USP tablet disintegration test apparatus (Pharma Test, Germany). The tablet was placed in $900 \mathrm{ml}$ distilled water maintained at $37^{\circ} \mathrm{C}$ and agitation speed of 30 shakes per min. Only one tablet at a time was tested. The tablet was considered disintegrated completely when all the particles passed through the screen. The disintegration time of 6 individual tablets were recorded and the average was reported. The disintegration time set by U.S. Food and Drug Administration (FDA) for all the ODT formulations $(<60 \mathrm{~s})$ were considered as a specification limit for sumatriptan succinate ODTs.

In Vitro Dissolution Studies In vitro dissolution studies of commercial product (Suminat ${ }^{\mathbb{B}}$, Sun Pharma, India) and ODT formulations were performed using USP XXIV type-II dissolution test apparatus (Distek Premiere, 5100, U.S.A.). The formulations, F10, F11, F15, F16, F25 and F28 which produced in vitro disintegration time less than $60 \mathrm{~s}$ were selected for dissolution studies. The dissolution medium and sampling time intervals were chosen according to USP official dissolution specification for sumatriptan succinate. ${ }^{7)}$ The study was conducted in $900 \mathrm{ml}$ of $0.01 \mathrm{~N} \mathrm{HCl}$ as a dissolution medium with paddle speed of $30 \mathrm{rpm}$ at a temperature of $37 \pm 0.5^{\circ} \mathrm{C}$. In addition, dissolution studies were also performed in acetate buffer $\mathrm{pH} 4.5$ and phosphate buffer $\mathrm{pH} 6.8$ at a similar paddle speed. Aliquots of dissolution medium $(5 \mathrm{ml})$ were withdrawn at specified intervals, $5,10,15,30,45$ and $60 \mathrm{~min}$ and replaced with an equal volume of fresh medium. The concentration of drug in samples was analyzed using UV/Visible spectrophotometer (Hitachi, Japan) at a wavelength of $227 \mathrm{~nm}$. Cumulative percent of drug release was calculated and plotted against time. The drug release profile of formulations was compared with that of the commercial product $\left(\right.$ Suminat ${ }^{\mathbb{B}}$ ). Dissolution studies were performed in replicates of six. The release profiles were characterized by dissolution efficiency (\%DE). A constant time intervals should be chosen for the comparison of dissolution data, whereby in this study $\mathrm{DE}_{15 \min }$ values were selected. $\mathrm{DE}$ was calculated by the following equation

$$
\text { dissolution efficiency (DE) }=\frac{\int_{0}^{t} y \times d t}{y_{100} \times t} \times 100 \%
$$

$y=$ drug percent dissolved at time $t$

Stability Studies The optimized formulation (F28) was examined at $40 \pm 2{ }^{\circ} \mathrm{C} / 75 \pm 5 \%$ relative humidity (RH) for accelerated stability and at $25 \pm 2{ }^{\circ} \mathrm{C} / 65 \pm 5 \% \mathrm{RH}$ for short term stability for a period of 6 months. The ODTs (F28) were packed and sealed in $30 \mathrm{cc}$ high density polyethylene (HDPE) bottles. ${ }^{6}$ Samples were withdrawn at 1, 3 and 6 months and evaluated for appearance, weight variation, thickness, hardness, friability, drug content, water content, disintegration time and dissolution. The drug was assayed using the previously reported HPLC-UV method. ${ }^{8)}$ The mobile phase was consisted of $20 \mathrm{~mm} \mathrm{KH}_{2} \mathrm{PO}_{4}(\mathrm{pH} 4.0)$ and acetonitrile $(65: 35$, v/v) delivered at $1.0 \mathrm{ml} / \mathrm{min}$ in $\mathrm{C} 4$ Hypersil column $(250 \times 4.6 \mathrm{~mm}, 5 \mu \mathrm{m})$. The detector wavelength was set at a wavelength of $227 \mathrm{~nm}$ and the injection volume was $50 \mu 1$.

Evaluation of Taste, Mouth Feel and in Vivo Disintegration Time in Human Volunteers The control formulation (F0) and optimized formulation (F28) containing superdisintegrant Kollidon CL-SF (5\%) were selected to assess taste, mouth feel and in vivo disintegration time in 12 healthy human volunteers at the age group of 25 to 33 years. The study protocol was approved by the Joint Ethics Committee of School of Pharmaceutical Sciences, Universiti Sains Malaysia and Hospital Lam Wah Ee. Prior to the test, all volunteers were informed of the purpose and protocol of the study and each volunteer gave his/her written consent to participate in the study. As per the protocol, all volunteers were asked to rinse their mouth with water before placing the tablet on the tongue and immediately a stopwatch was 


\begin{tabular}{|c|c|c|c|c|c|c|c|c|c|c|c|c|c|c|c|c|}
\hline$\frac{n}{I}$ & | | 官苍 | & 용 & & $\stackrel{\text { iे }}{\text { m. }}$ & 1 & I & $\overbrace{}^{1}$ & $\stackrel{+}{i} \stackrel{+}{i}$ & $\overrightarrow{\underline{9}}$ & : & | & & | & \multicolumn{3}{|c|}{ ○ } \\
\hline$\underset{I}{\Delta}$ & 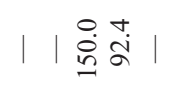 & $\div$ is & & $\stackrel{\circ}{i}$ & | & | & ţ & $\stackrel{\dot{i}}{i} \stackrel{+}{i}$ & 胥 & 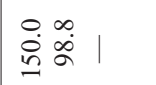 & | & & । & | & & : \\
\hline$\frac{m}{I}$ & 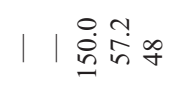 & । & $\stackrel{0}{\dot{0}}$ & $\stackrel{\text { ì }}{\text { in }}$ & I & | & ค ㅇํㅇ & $\stackrel{i}{i} \stackrel{i}{i}$ & त्ञ & ํํㅇำ & 1 & & । & I & & 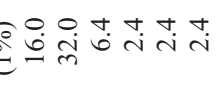 \\
\hline$\frac{\sqrt{I}}{2}$ & | | & | & $\stackrel{0}{\dot{0}}$ & 리 & I & I & 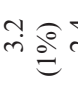 & $\stackrel{i}{i} \stackrel{i}{i}$ & $\underset{N}{\infty}$ & 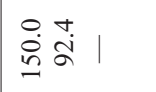 & । & & । & $\dot{\circ} \dot{\circ}$ & ci & 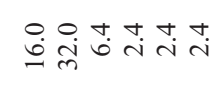 \\
\hline 压 & 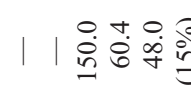 & & $\stackrel{0}{0}$ & ì & । & I & ti. & $\stackrel{i}{i} \stackrel{i}{i}$ & $\hat{i}$ & 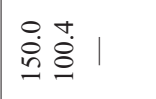 & । & & । & is & $\sum_{1}^{\infty}$ & 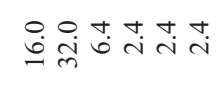 \\
\hline 올 & | | & & $\stackrel{\ddot{\theta}}{0}$ & $\stackrel{\text { i }}{m}$ & | & | & $\ddot{t}$ & 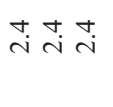 & స్1 & 官芒| & । & & I & 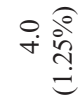 & & 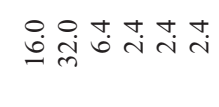 \\
\hline 至 & | | & & $\stackrel{0}{0}$ & ì & 1 & 1 & ఫ̧ & 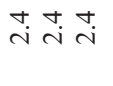 & 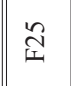 & 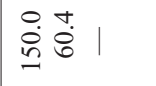 & । & । & & ह & । & 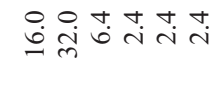 \\
\hline$\infty$ & | | & | & $\stackrel{\circ}{\circ}$ & 욤 & 1 & | & ఫ̧ & $\stackrel{+}{i} \stackrel{⿱}{i}$ & 空 & 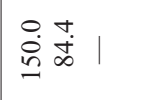 & । & । & ㄴํㄹㄹ & & । & 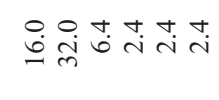 \\
\hline 桴 & | | & । & $\stackrel{\circ}{\dot{0}}$ & 1 & I & & ఫ̈. & $\stackrel{+}{i} \stackrel{⿱}{i}$ & & 록 & 1 & & 용 & $\frac{1}{2}$ & । & 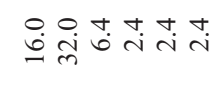 \\
\hline 度 & | | & । & $\stackrel{\circ}{\dot{0}}$ & 1 & iे & I & ţ. & 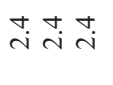 & तิ & 官苛| & I & & & I & । & 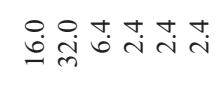 \\
\hline in & | | & । & $\stackrel{\circ}{\dot{\omega}}$ & 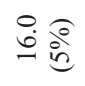 & 1 & I & تु. & 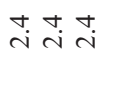 & $\overrightarrow{\widehat{I}}$ & 官苍| & I & $\approx \stackrel{\widehat{\circ}}{=}$ & & 1 & । & 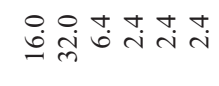 \\
\hline 石 & | | & । & : & i & I & I & $\stackrel{t}{6}$ & 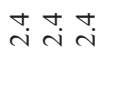 & ్ㅗ & 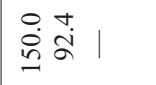 & । & 용 & & । & । & 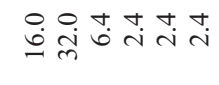 \\
\hline$m$ & 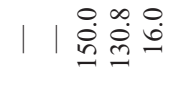 & । & 용 & 1 & I & I & $\vec{b}$ & 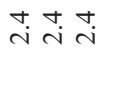 & $\frac{\partial}{\partial}$ & 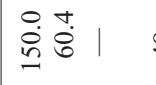 & & & । & I & । & 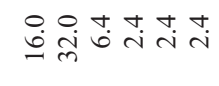 \\
\hline I & | | & | & กั & 1 & I & | & 它 & $\stackrel{+}{i} \stackrel{⿱}{i}$ & $\stackrel{\infty}{\vec{I}}$ & :̊ं & $\sim \stackrel{\widehat{\circ}}{=}$ & bi & । & | & । & Oِ \\
\hline$\vec{I}$ & | | & | & | & I & । & | & 象 & 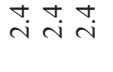 & $\vec{I}$ & : & 용 & है। & । & | & । & 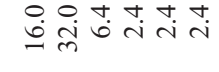 \\
\hline 厌 & 요 $\mid$ inㅇ & । & I & | & I & I & 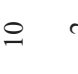 & $N \sim N$ & $\frac{0}{1}$ & 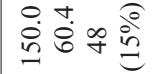 & i & । & । & I & | & 苞 \\
\hline 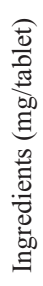 & 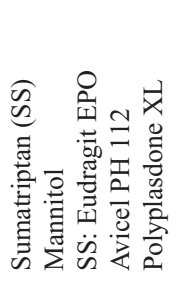 & $\begin{array}{l}\stackrel{0}{1} \\
\dot{\vec{x}} \\
0 \\
0 \\
\frac{0}{0} \\
\frac{0}{0} \\
\frac{0}{2} \\
\frac{\pi}{0}\end{array}$ & 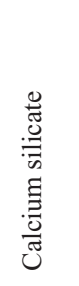 & 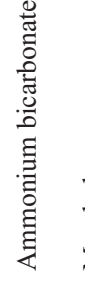 & 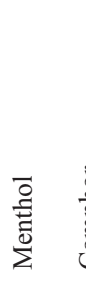 & 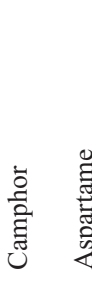 & : & 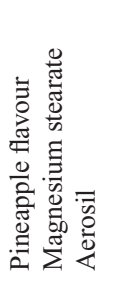 & 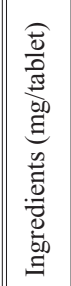 & 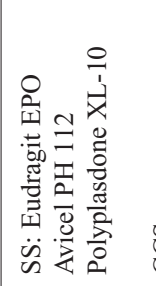 & U & D & 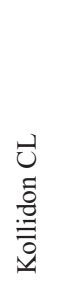 & 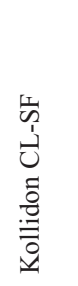 & 曾 & 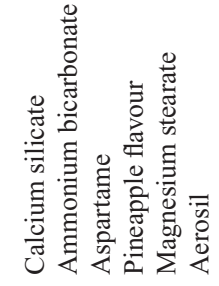 \\
\hline
\end{tabular}


started. Volunteers were allowed to move the tablet against the upper palate of the mouth with their tongue and to cause a gentle tumbling action on the tablet without biting on it or tumbling it from side to side. The taste and mouth feel were evaluated based on the volunteers' spontaneous verbal judgments immediately after the tablet was placed in their mouth as well as after $3-4 \mathrm{~min}$. The taste and mouth feel were rated on a scale of 1 through 5. In taste evaluation, ' 1 ' was considered to be "good" while a ' 5 ' was considered as "awful." In the mouth feel evaluation, ' 1 ' was considered to be "good" while a '5' was considered as "high grittiness." Time taken for the volunteer to feel that the last noticeable granule or fragment had disintegrated in the oral cavity was considered as the in vivo disintegration time. The volunteers were prohibited swallowing of their saliva during the test and instructed to rinse their mouth after measurement.

In Vivo Study The study was carried out in accordance with Animal Ethical Guidelines for investigations in laboratory animal and the study protocol was approved by the Animal Ethics Committee of Universiti Sains Malaysia. Six healthy male New Zealand white rabbits weighing between $2.8-3.4 \mathrm{~kg}$ were used for the in vivo study. The study was conducted according to a 2-period, 2-sequence crossover design with one week wash out period between the phases. The rabbits were randomly divided into two groups of three rabbits each. All the rabbits were fasted for $12 \mathrm{~h}$ with ad libitum access to water. One group received Reference product (Suminat ${ }^{\circledR}$ ) whereas the other group received Test formulation (F28).

The tablets were administered to the rabbits using a procedure reported by Ishikawa et al. ${ }^{9)}$ The tablets were administered at the back of the pharynx using a gastric intubation tube (made of silicone rubber) with one tablet set on the tip of the tube and immediately $5 \mathrm{ml}$ of water was administered through the tube to facilitate swallowing of the tablet and to prevent it from sticking to the rabbit's throat. Two milliliters of blood sample was withdrawn from marginal ear vein into heparinized Eppendorf tubes at time intervals of 0 (pre-dose), $0.25,0.5,0.75,1,1.5,2,3,4,6,8,12$ and $16 \mathrm{~h}$ post administration. The blood was immediately centrifuged at $4000 \mathrm{rpm}$ for $15 \mathrm{~min}$ and plasma was stored at $-20^{\circ} \mathrm{C}$ until HPLC analysis.

To $0.5 \mathrm{ml}$ aliquot of plasma, $20 \mu \mathrm{l}$ of $1 \mu \mathrm{g} / \mathrm{ml}$ of sulpiride dissolved in methanol was added as an internal standard and then added $0.5 \mathrm{ml}$ of $1 \mathrm{M}$ sodium hydroxide and $7 \mathrm{ml}$ mixture of TBME, DCM and EA $(2: 2: 3$, v/v) as an extraction solvent. The mixture was vortexed for $2 \mathrm{~min}$ and centrifuged at $4000 \mathrm{rpm}$ for $15 \mathrm{~min}$. The supernatant was transferred to a reacti-vial and evaporated to dryness at $50^{\circ} \mathrm{C}$ under a gentle stream of nitrogen gas. The residue was reconstituted with $0.2 \mathrm{ml}$ of $10 \% \mathrm{v} / \mathrm{v}$ methanol and $50 \mu \mathrm{l}$ of the sample was injected into the HPLC system. The HPLC system consisted of a Shimadzu chromatographic system (Kyoto, Japan) equipped with an LC20AD solvent delivery binary pump, RF-10AXL fluorescence detector, SIL20AHT autosampler, CTO-10AS VP column oven and LC Solution software for data acquisition and processing. Chromatographic separations were performed using a reversed-phase C4 analytical column (Phenomenex Kromasil, $250 \times 4.6 \mathrm{~mm}, 5 \mu \mathrm{m}$ ) fitted with a $\mathrm{C} 4$ guard column (Phenomenex Kromasil, $10 \times 4 \mathrm{~mm}, 5 \mu \mathrm{m})$. The mobile phase was $25 \mathrm{~mm}$ ammonium acetate $(\mathrm{pH} 6.5)$ and acetonitrile $(85: 15, \mathrm{v} / \mathrm{v})$ and delivered at a flow rate of $0.9 \mathrm{ml} / \mathrm{min}$. Fluorescence detection was performed with excitation wavelength $225 \mathrm{~nm}$ and emission wavelength $350 \mathrm{~nm}$. The column oven temperature was maintained at $40^{\circ} \mathrm{C}$. The calibration curve exhibited an excellent linearity over a concentration range of $1-300 \mathrm{ng} / \mathrm{ml}$ of sumatriptan with a correlation coefficient of 0.9999 .

The pharmacokinetic parameters, namely, maximum plasma concentration $\left(C_{\max }\right)$ and time to reach $C_{\max }\left(T_{\max }\right)$ were obtained directly from the plasma concentration-time data. The area under the plasma concentrationtime curve from 0 to $16 \mathrm{~h}\left(A U C_{0-16 \mathrm{~h}}\right)$ was calculated by the trapezoidal rule.

Statistical Analysis The results are reported as mean \pm standard deviation (S.D.). The in vitro disintegration time, $\% \mathrm{DE}$ values for in vitro release profiles of sumatriptan succinate and all the physical properties of stability samples were treated statistically using one-way analysis of variance (ANOVA). When there was a statistically significant difference, a post hoc Tukey's honestly significant difference (HSD) test was performed. The pharmacokinetic parameters, $C_{\max }$ and $A U C_{0-16 \mathrm{~h}}$ were analyzed statistically using one way analysis of variance (ANOVA) which distinguishes effects due to subjects, periods and treatment. ${ }^{10)}$ The $p$ value was calculated from the obtained $F$ value using GraphPad Prism, version 5.02 (GraphPad Prism software, San Diego, CA, U.S.A.). The values of $C_{\max }$ and $A U C_{0-16 \mathrm{~h}}$ were logarithmic transformed before analysis. The $T_{\max }$ values were analyzed using Wilcoxon Signed Rank test for paired samples. A statistical significant difference was considered at $p<0.05$.

\section{Results and Discussion}

Taste Masking of Sumatriptan Succinate The two key parameters that need to be considered in the development of ODTs are taste masking of bitter drug and the disintegration time. In the development of ODT formulations, the prime challenges are to mask the bitter taste of an active, especially a water-soluble compound and to optimize a formulation that will dissolve in the oral cavity in less than a minute.

Sumatriptan succinate is a highly water soluble and intensely bitter drug. Spray drying technique was used for the taste masking of sumatriptan succinate by coating the drug with Eudragit EPO polymer because it requires only a onestep process and can be easily controlled and scaled up. Eudragit EPO was used as a taste masking agent because it dissolves at a $\mathrm{pH}$ of less than 5. Therefore, it does not dissolve in the buccal cavity ( $\mathrm{pH} 5.8-7.4)$ and keeps the coated drug intact to produce good taste masking, but the polymer dissolves in the stomach $(\mathrm{pH} 1-3)$ to release the drug. ${ }^{11)}$ The prepared microspheres were evaluated for in vitro taste masking in $5 \mathrm{ml}$ of phosphate buffer $\mathrm{pH} 6.8$. The results showed that about $13.82 \pm 0.43,7.62 \pm 0.50$ and $4.57 \pm 0.27 \%$ of the drug was released from the microspheres in $60 \mathrm{~s}$ at the drug to polymer ratios of $1: 0.50,1: 0.75$ and $1: 1$, respectively. Among the three ratios of drug to polymer, the microspheres prepared with a ratio of $1: 1$ released less than $5 \%$ of drug in $60 \mathrm{~s}$. The drug release would further decrease as the disintegration time of the ODT is less than $60 \mathrm{~s}$. Hence, the microspheres prepared with a ratio of $1: 1$ could be sufficient to mask the bitter taste of sumatriptan succinate in the ODT preparations and used for further evaluation.

Evaluation of Spray Dried Microspheres. Thermal Analysis Figure 1 shows the characteristic endothermic peaks of Eudragit EPO and sumatriptan succinate which represent their melting points. The reported sumatriptan succinate melting point in literature is $169-171^{\circ} \mathrm{C}$. ${ }^{12)}$ The DSC analysis of spray dried microspheres at a drug to polymer ratio of $1: 1$ revealed negligible change in melting points of Eudragit EPO and sumatriptan succinate, indicating no interaction between the drug and polymer (Fig. 1C). Thus, the findings suggest that the drug was compatible with the polymer used and it did not undergo any changes during the spray drying process.

Particle Size The mean particle size of the spray dried microspheres was $7.77 \pm 0.22 \mu \mathrm{m}$. The particle size of the microspheres was considered to be suitable for preparation of orally disintegrating tablets as it would produce a smooth mouth feel without grittiness in the mouth when administered in the form of a tablet.

Entrapment Efficiency, Drug Loading and Yield The entrapment efficiency of the microspheres was found to be $92.86 \pm 0.68 \%$ with a drug loading of $46.43 \pm 0.56 \%$. The yield of the spray dried microspheres was about $56.34 \%$. The low yield could be due to a smaller portion of small and light particles which escaped through the exhaust of the spray dryer during the spray-drying process. The yield of the microspheres may be further improved if the loss of particles through the exhaust of the spray dryer apparatus can be prevented. ${ }^{11)}$

Evaluation of Tablets The average weight and thickness of tablets for all the formulations was found to be in the range of 316.29 to $323.45 \mathrm{mg}$ and 6.34 to $6.58 \mathrm{~mm}$, respec- 


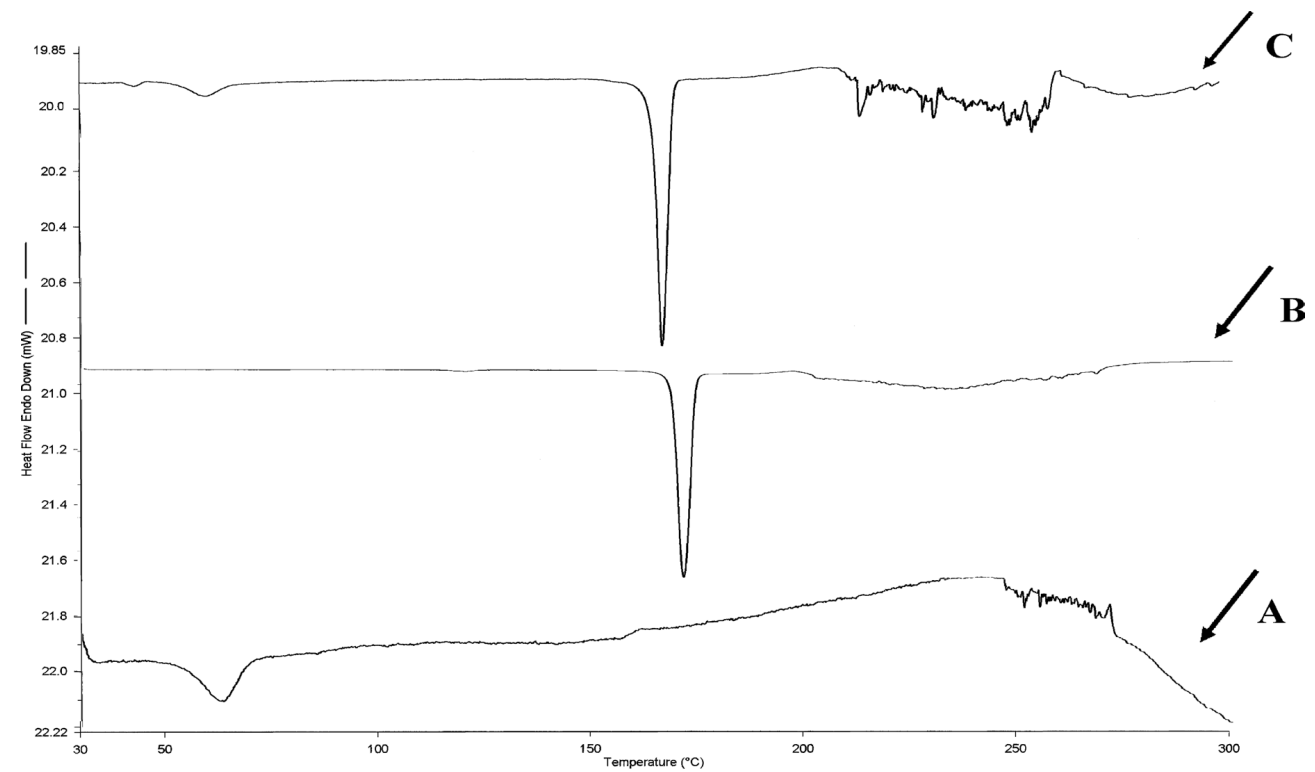

Fig. 1. DSC Thermograms of (A) Eudragit EPO, (B) Sumatriptan Succinate, (C) Sumatriptan Succinate and Eudragit EPO Spray Dried Microspheres

Table 2. Results of Various Formulations of Sumatriptan Succinate ODTs. Mean \pm S.D.

\begin{tabular}{|c|c|c|c|c|c|c|c|}
\hline Formulation & $\begin{array}{l}\text { Weight variation } \\
\quad(\mathrm{mg}) ; n=20\end{array}$ & $\begin{array}{c}\text { Thickness } \\
(\mathrm{mm}) ; n=10\end{array}$ & $\begin{array}{c}\text { Hardness } \\
(\mathrm{kg}) ; n=10\end{array}$ & $\begin{array}{l}\text { Friability } \\
(\%) ; n=20\end{array}$ & $\begin{array}{l}\text { Drug content } \\
(\%) ; n=3\end{array}$ & $\begin{array}{l}\text { In vitro } \mathrm{DT}^{a)} \\
\quad(\mathrm{s}) ; n=6\end{array}$ & $\begin{array}{l}\text { Water content } \\
\quad(\%) ; n=3\end{array}$ \\
\hline $\mathrm{F} 1$ & $319.39 \pm 3.01$ & $6.38 \pm 0.09$ & $2.67 \pm 0.14$ & 0.33 & $100.77 \pm 1.23$ & $409.17 \pm 10.91$ & - \\
\hline $\mathrm{F} 2$ & $320.14 \pm 1.11$ & $6.42 \pm 0.03$ & $2.70 \pm 0.13$ & 0.29 & $100.55 \pm 0.89$ & $354.00 \pm 5.29$ & - \\
\hline F3 & $321.11 \pm 1.50$ & $6.49 \pm 0.07$ & $2.55 \pm 0.14$ & 0.51 & $101.24 \pm 1.36$ & $264.83 \pm 5.98$ & - \\
\hline $\mathrm{F} 4$ & $318.70 \pm 1.05$ & $6.35 \pm 0.04$ & $2.49 \pm 0.09$ & 0.55 & $98.87 \pm 0.91$ & $229.50 \pm 6.50$ & - \\
\hline F5 & $318.63 \pm 1.74$ & $6.36 \pm 0.02$ & $2.60 \pm 0.13$ & 0.42 & $99.09 \pm 1.12$ & $164.83 \pm 4.36$ & - \\
\hline F6 & - & - & - & - & - & - & - \\
\hline F7 & - & - & - & - & - & - & - \\
\hline F8 & $319.96 \pm 0.87$ & $6.37 \pm 0.08$ & $2.46 \pm 0.10$ & 0.59 & $99.69 \pm 0.99$ & $121.33 \pm 2.16$ & - \\
\hline F9 & $317.21 \pm 1.58$ & $6.48 \pm 0.09$ & $2.72 \pm 0.12$ & 0.33 & $98.56 \pm 1.05$ & $71.50 \pm 1.87$ & - \\
\hline F10 & $316.29 \pm 2.13$ & $6.47 \pm 0.05$ & $2.47 \pm 0.16$ & 0.65 & $98.23 \pm 1.48$ & $55.67 \pm 2.07$ & $7.67 \pm 0.06$ \\
\hline F11 & $319.85 \pm 1.43$ & $6.37 \pm 0.06$ & $2.53 \pm 0.15$ & 0.42 & $100.77 \pm 1.14$ & $39.17 \pm 1.83$ & $7.83 \pm 0.06$ \\
\hline F12 & $320.85 \pm 0.99$ & $6.41 \pm 0.06$ & $2.51 \pm 0.07$ & 0.68 & $99.96 \pm 0.74$ & $38.00 \pm 1.10$ & - \\
\hline F13 & $320.34 \pm 1.41$ & $6.44 \pm 0.05$ & $2.36 \pm 0.05$ & 0.72 & $100.33 \pm 0.81$ & $39.50 \pm 1.64$ & - \\
\hline F14 & $317.64 \pm 1.87$ & $6.41 \pm 0.05$ & $2.51 \pm 0.21$ & 0.62 & $99.11 \pm 0.57$ & $63.67 \pm 1.63$ & - \\
\hline F15 & $321.93 \pm 2.11$ & $6.37 \pm 0.08$ & $2.49 \pm 0.24$ & 0.69 & $100.43 \pm 1.09$ & $37.50 \pm 1.52$ & $8.19 \pm 0.05$ \\
\hline F16 & $317.28 \pm 1.59$ & $6.56 \pm 0.08$ & $2.53 \pm 0.19$ & 0.59 & $99.19 \pm 0.73$ & $38.50 \pm 1.38$ & $8.72 \pm 0.04$ \\
\hline F17 & $320.14 \pm 1.73$ & $6.40 \pm 0.11$ & $2.71 \pm 0.10$ & 0.37 & $100.47 \pm 1.16$ & $64.33 \pm 1.75$ & - \\
\hline F18 & $322.18 \pm 1.19$ & $6.53 \pm 0.03$ & $2.74 \pm 0.15$ & 0.30 & $102.31 \pm 1.48$ & $86.33 \pm 1.97$ & - \\
\hline F19 & $316.49 \pm 1.80$ & $6.37 \pm 0.08$ & $2.40 \pm 0.17$ & 0.64 & $98.50 \pm 0.71$ & $136.00 \pm 2.19$ & - \\
\hline $\mathrm{F} 20$ & $319.33 \pm 1.93$ & $6.44 \pm 0.05$ & $2.42 \pm 0.14$ & 0.59 & $100.27 \pm 0.84$ & $111.83 \pm 3.19$ & - \\
\hline F21 & $323.32 \pm 1.52$ & $6.39 \pm 0.08$ & $2.56 \pm 0.11$ & 0.59 & $102.56 \pm 1.31$ & $148.00 \pm 2.37$ & - \\
\hline $\mathrm{F} 22$ & $318.46 \pm 1.48$ & $6.58 \pm 0.09$ & $2.55 \pm 0.22$ & 0.61 & $100.27 \pm 0.62$ & $190.33 \pm 2.16$ & - \\
\hline F23 & $321.76 \pm 2.04$ & $6.34 \pm 0.02$ & $2.54 \pm 0.17$ & 0.56 & $100.93 \pm 0.95$ & $75.00 \pm 1.90$ & - \\
\hline $\mathrm{F} 24$ & $319.11 \pm 1.75$ & $6.47 \pm 0.10$ & $2.49 \pm 0.13$ & 0.61 & $100.38 \pm 1.21$ & $64.33 \pm 1.21$ & - \\
\hline F25 & $317.76 \pm 2.22$ & $6.48 \pm 0.07$ & $2.67 \pm 0.06$ & 0.39 & $99.39 \pm 1.03$ & $48.17 \pm 2.32$ & $6.35 \pm 0.05$ \\
\hline F26 & $316.29 \pm 1.92$ & $6.39 \pm 0.06$ & $2.56 \pm 0.20$ & 0.39 & $98.11 \pm 0.36$ & $73.00 \pm 1.55$ & - \\
\hline $\mathrm{F} 27$ & $323.45 \pm 1.04$ & $6.41 \pm 0.03$ & $2.63 \pm 0.19$ & 0.46 & $102.45 \pm 1.17$ & $62.83 \pm 1.33$ & - \\
\hline F28 & $317.98 \pm 1.10$ & $6.43 \pm 0.03$ & $2.46 \pm 0.18$ & 0.54 & $99.05 \pm 0.79$ & $38.17 \pm 1.47$ & $6.41 \pm 0.04$ \\
\hline F29 & $317.43 \pm 1.44$ & $6.54 \pm 0.02$ & $2.41 \pm 0.16$ & 0.63 & $99.83 \pm 0.68$ & $155.50 \pm 2.74$ & - \\
\hline F30 & $317.28 \pm 1.28$ & $6.47 \pm 0.04$ & $2.65 \pm 0.15$ & 0.42 & $100.06 \pm 1.22$ & $133.33 \pm 2.73$ & - \\
\hline F31 & $322.09 \pm 1.82$ & $6.50 \pm 0.09$ & $2.76 \pm 0.09$ & 0.28 & $101.89 \pm 0.73$ & $112.00 \pm 1.90$ & - \\
\hline
\end{tabular}

a) In vitro DT: In vitro disintegration time.

tively (Table 2). All the formulations exhibited low weight variation which lies within the USP pharmacopoeial limits of $\pm 7.5 \%$ of the average weight. ${ }^{7)}$ The hardness of the tablets was maintained in the range of $2-3 \mathrm{~kg}$ and the friability results were found to be within the acceptable limits $(<1 \%)$ which suggested that ODTs ability to withstand abrasion in handling, packaging and shipment. All the formulations demonstrated uniformity in the assay and drug content varied from 98.11 to $102.56 \%$. The formulations with a disintegration time of less than $60 \mathrm{~s}$ were subjected to water content de- 
termination. The water content of all the ODT formulations was found to be less than $9 \%$.

Effect of Pore Forming Agent The disintegration time of the tablets prepared with formulation F1 was very high and not within the acceptable limits $(<60 \mathrm{~s})$ of ODT specifications set by USFDA. Hence, calcium silicate, a highly porous, lightweight powder was incorporated as a pore forming agent in the next formulations to decrease the disintegration time of the tablets. Calcium silicate was used in a concentration range of 1 to $5 \%$ (F2 to $\mathrm{F} 4$ ). The concentration of calcium silicate had no effect on the physical properties of the tablets but influenced the disintegration time (Table 2). The disintegration time of tablets were decreased significantly $(p<0.05)$ with respect to increase in the concentration of calcium silicate from 1 to 3 and 5\%. It might be due to the increase in the amount of calcium silicate in the formulations increasing the porous nature of the tablets which lead to a faster absorption of water through the pores by wicking action and disintegration of the tablets. ${ }^{13)}$ However, formulations F2 to F4 did not meet the disintegration time requirements set by USFDA. Therefore, in the next experiments, sublimation technique was used to achieve the desired disintegration time of $<60 \mathrm{~s}$.

Effect of Subliming Agent Type and Concentration The effect of subliming agent type was studied by preparing the formulations containing ammonium bicarbonate (F5), menthol (F6) and camphor (F7) at a concentration of $5 \%$. Many researchers reported that the sublimation of tablet containing subliming agent provided faster disintegration time compared to sublimation directly from the granules. ${ }^{14-16)}$ It could be explained that a compaction process during tableting might have caused breakage of porous granules and subsequent reduction in porosity. ${ }^{17,18)}$ Hence, in the present study, sublimation process was carried out from the tablets instead of from the granules. The tablets prepared with ammonium bicarbonate (F5) were disintegrated in $164.83 \mathrm{~s}$ and produced a pronounced decrease in disintegration time of the tablets when compared to formulation F4 (229.50 s). It could be due to the addition of ammonium bicarbonate increased the porosity of the tablet. Surprisingly, the formulations containing menthol (F6) and camphor (F7) formed wet mass which may be due to formation of eutectic mixture between one of the excipients or drug itself or their combination with camphor or menthol. ${ }^{19)}$ As the wet mass was not suitable to produce tablets, ammonium bicarbonate was therefore selected for the next formulations.

Ammonium bicarbonate in different concentrations, 5\% (F5), 7.5\% (F8) and 10\% (F9) were incorporated as a subliming agent. Sublimation process was carried out for $15-21 \mathrm{~h}$ at $40{ }^{\circ} \mathrm{C}$ depended on the amount of ammonium bicarbonate present in the formulations. Increasing the concentration of subliming agent in the formulations did not show any effect on physical properties of the tablets, but decreased the disintegration time of the tablets significantly from 164.83 (F5) to 121.33 (F8) and $71.50 \mathrm{~s}$ (F9). The tablets containing 10\% ammonium bicarbonate produced faster disintegration which could be due to higher porosity of tablets. During drying, ammonium bicarbonate sublimed and could be formed porous structure on the surface of the tablets. ${ }^{20)}$ The porous structure is responsible for faster water uptake which facilitates wicking action of Polyplasdone XL in bringing about faster disintegration of tablet. ${ }^{18,21)}$ Although, sublimation method produced lower disintegration time results, the tablets have yet to achieve the desired disintegration time specified for ODTs by USFDA.

Effect of Type and Concentration of Superdisintegrant The different concentrations and types of superdisintegrants used in the formulations did not show any effect on the physical properties but influenced the disintegration time of the tablets (Table 2). The disintegration time of various formulations prepared with different types and concentrations of superdisintegrants varied from 37.50 to $190.33 \mathrm{~s}$. The disintegration time of the tablets decreased significantly with the increase in the concentration of Polyplasdone XL from 5 (F9) to 10 (F10) and $15 \%$ (F11). Increase in the concentration of Polyplasdone XL-10 from 5 (F14) to $10 \%$ (F15) resulted in a significant decrease $(p<0.05)$ in the disintegration time of the tablets. However, further increase in the concentration to $15 \%$ (F16) did not show any significant effect $(p>0.05)$ on the disintegration time of the tablets.

When the superdisintegrants, Polyplasdone XL and XL-10 were replaced with CCS and SSG at a concentration level of 5\% (F17 and F20), the disintegration time of the tablets was 64.33 and $111.83 \mathrm{~s}$, respectively. Further increase in the concentration of CCS and SSG from 5 to 10 (F18 and F21) and $15 \%$ (F19 and F22) resulted in a significant increase $(p<0.05)$ in the disintegration time of the tablets. It can be observed from the results that the disintegration of tablets containing crospovidone (Polyplasdone XL and Polyplasdone XL-10) were comparatively faster than those containing CCS and SSG at the same concentration level. It might be attributed to rapid water absorbing nature of crospovidone, involving both capillary and swelling mechanisms which build up the pressure internally leading to the faster disintegration. ${ }^{22}$ ) This dissimilarity in behaviour of crospovidone, CCS and SSG on the disintegration time can be attributed to the difference in their mechanism of disintegration. The concentration of crospovidone had a positive effect on the disintegration of tablets. Increasing the concentration of crospovidone resulted in a faster disintegration of tablets, which may be due to rapid capillary activity and pronounced hydration with little tendency for gel formation. ${ }^{23,24)}$ On the contrary, when the concentration of CCS and SSG was increased it had a negative effect on the disintegration of the tablets. This negative effect may be due to the formation of a viscous gel layer by CCS and SSG which may impede further penetration of the disintegration medium and hindered the disintegration of tablets. $^{24,25)}$ The obtained results were similar to the findings of Khan et al. ${ }^{26)}$ and Patel et al. ${ }^{27)}$

The disintegration time of the tablets was significantly decreased $(p<0.05)$ with increase in the concentration of Kollidon CL from 5 to $10 \%$ (F23 to F25) and Kollidon CL-SF from 1.25 to $5 \%$ (F26 to F28). The tablets prepared with formulation F28 produced shorter disintegration time results compared to formulation F25. These superdisintegrants exhibited their disintegrant effect by wicking action without forming a gel. They increase the porosity and provide pathways for the penetration of fluids into tablets, which in turn resulted in wicking through capillary action facilitating the disintegration of tablets. ${ }^{28)}$ An increase in the superdisintegrant, L-HPC concentration from 1 (F29) to 3 (F30) and 5\% (F31) resulted in a significant decrease in the disintegration 
time of tablets. The tablets prepared with L-HPC disintegrated based on its swelling property in water. ${ }^{29)}$

Amount of Aspartame in Preparation of ODTs Aspartame was incorporated as a sweetener in the formulations to produce sufficient sweet taste of the tablets. In the process of formulation optimization, the first formulation which produced disintegration time of less than $60 \mathrm{~s}$ was selected for the incorporation of different concentrations of sweetener. Although, the formulation F10 was the first formulation which was able to disintegrate in less than $60 \mathrm{~s}(55.67 \mathrm{~s})$, the formulation F11 was selected for this study as this formulation produced lower disintegration time (39.17 s) compared to the former. Preliminary studies were performed in healthy human volunteers for the taste characterization of sumatriptan succinate ODTs prepared with different amount of aspartame ( 1 to $3 \%)$ as a sweetener in the formulations F12, F11 and F13. The physical properties of the tablets including disintegration time were not affected by the concentration of aspartame in the formulations (Table 2). The optimum amount of sweetener was determined based on the taste perception. A single blind study was designed for the taste masking test. Six healthy human volunteers in the age group of $25-33$ years participated in the test. The evaluation was based on the extent to which subjects liked the taste of each ODT. Among the 6 volunteers, 4 volunteers rated the formulation F12 containing $1 \%$ aspartame as ' 2 ,' indicating the formulation had no taste, 1 volunteer rated as ' 1 ' indicating a sweet taste and 1 volunteer rated as ' 3 ' indicating a slight bitterness of tablets. All the volunteers rated the formulation F11 and F13 as '1,' suggesting that these formulations were sweet and acceptable. Hence, it was concluded that formulations F11 and F13 with 2 and $3 \%$ of aspartame successfully produced sweet taste of sumatriptan succinate ODTs and the amount of aspartame used was also well within the limits of USFDA. ${ }^{30}$ Thus, $2 \%$ aspartame was incorporated in all other formulations.

In Vitro Dissolution Studies The commercial product $\left(\right.$ Suminat $^{\circledR}$ ) released more than $90 \%$ of drug in $15 \mathrm{~min}$ in $0.01 \mathrm{~N} \mathrm{HCl}$ and phosphate buffer $\mathrm{pH} 6.8$ and $10 \mathrm{~min}$ in acetate buffer $\mathrm{pH}$ 4.5. All the ODT formulations (F10, F11, F15, F16, F25 and F28) exhibited similar release profiles with commercial product (Fig. 2) and showed no significant difference in the $\mathrm{DE}_{15 \mathrm{~min}}$ values irrespective of the dissolution media (Table 3).

Although all the formulation release profiles were comparable with the commercial product irrespective of the dissolution media, formulation F28 was selected as an optimized formulation due to the smaller particle size $(10-30 \mu \mathrm{m})$ of the superdisintegrant, Kollidon CL-SF compared to other superdisintegrants used in this study. The smaller particle size of Kollidon CL-SF would produce a tablet with smooth mouth feel without grittiness in the mouth when administered to the patient. Moreover, the tablets prepared with Kollidon CL-SF produced lower water content results compared to Polyplasdone XL and Polyplasdone XL-10 and similar to Kollidon CL (Table 2). The amount of water content present in the ODTs significantly affects the stability of the final drug product. Hence, this lower water content could be an added advantage in increasing the stability of the final drug product.

Evaluation of Taste, Mouth Feel and in Vivo Disinte-
(A)

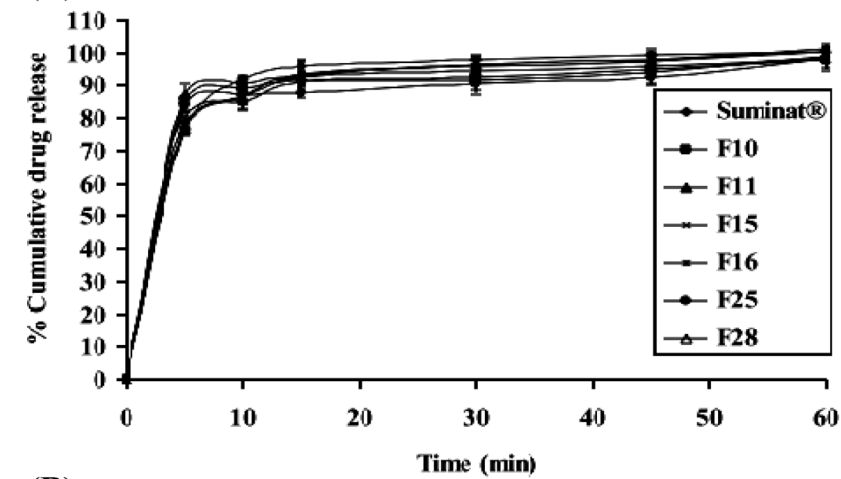

(B)

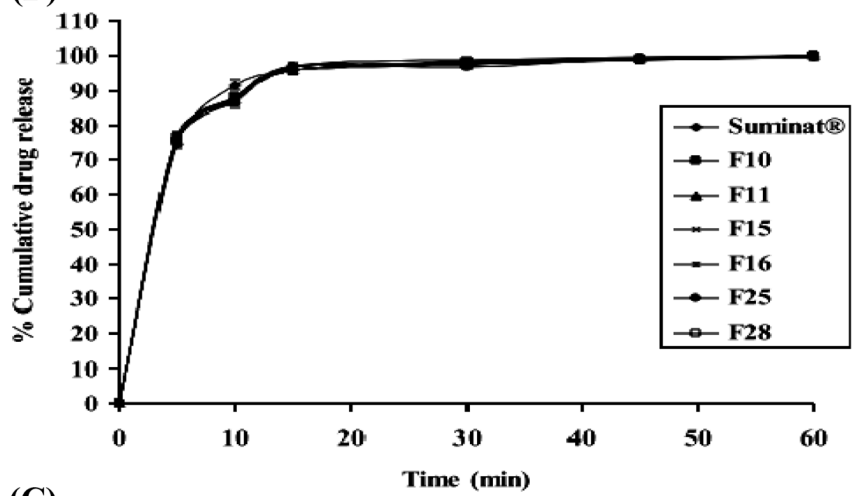

(C)

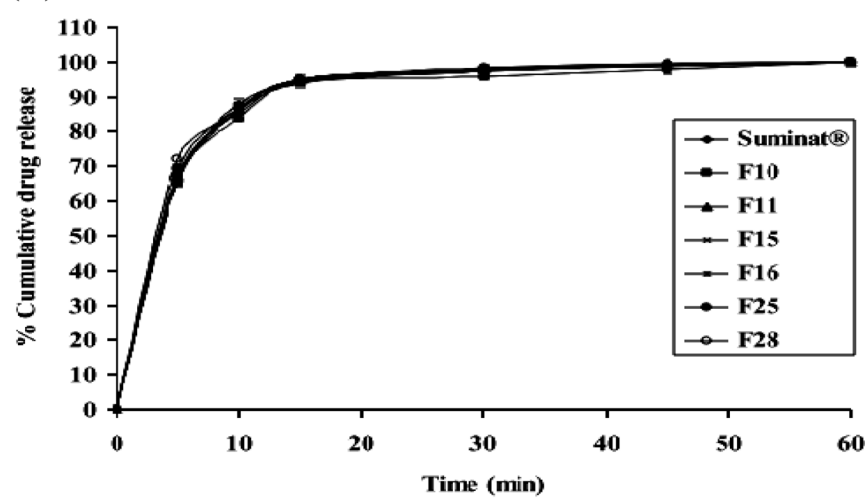

Fig. 2. In Vitro Release Profiles of Formulations F10 (10\% Polyplasdone XL), F11 (15\% Polyplasdone XL), F15 (10\% Polyplasdone XL-10), F16 (15\% Polyplasdone XL-10), F25 (10\% Kollidon CL), F28 (5\% Kollidon CL$\mathrm{SF}$ ) and Commercial Product $\left(\right.$ Suminat $^{\mathbb{R}}$ ) in (A) $0.01 \mathrm{~N} \mathrm{HCl}$, (B) Acetate Buffer $\mathrm{pH} 4.5$, (C) Phosphate Buffer $\mathrm{pH} 6.8$

Mean \pm S.D., $n=6$.

Table 3. Dissolution Efficiency (DE) Results of Sumatriptan Succinate ODTs in Different Dissolution Media at a Paddle Speed of $30 \mathrm{rpm}$

\begin{tabular}{cccc}
\hline \hline & \multicolumn{3}{c}{$\mathrm{DE}_{15 \min }(\%)$} \\
\cline { 2 - 4 } Formulation & $0.01 \mathrm{~N} \mathrm{HCl}$ & $\begin{array}{c}\text { Acetate buffer } \\
\mathrm{pH} 4.5\end{array}$ & $\begin{array}{c}\text { Phosphate buffer } \\
\mathrm{pH} 6.8\end{array}$ \\
& & & $66.94 \pm 0.73$ \\
& & $71.45 \pm 1.04$ & $65.85 \pm 0.54$ \\
Suminat $^{\circledR}$ & $72.19 \pm 0.44$ & $70.23 \pm 0.89$ & $67.02 \pm 0.70$ \\
F10 & $73.66 \pm 0.46$ & $70.31 \pm 0.61$ & $66.77 \pm 1.04$ \\
F15 & $74.95 \pm 1.43$ & $70.42 \pm 0.73$ & $66.17 \pm 1.21$ \\
F16 & $70.15 \pm 1.04$ & $71.13 \pm 0.72$ & $67.84 \pm 1.00$ \\
F25 & $70.46 \pm 2.57$ & $70.15 \pm 0.71$ & $68.17 \pm 0.93$ \\
F28 & $61.70 \pm 1.40$ & $70.53 \pm 0.72$ &
\end{tabular}

Mean \pm S.D., $n=6$. 
gration Time in Human Volunteers All the volunteers reported that the control formulation (F0) was very bitter in taste and immediately spitted out the tablet. Hence, mouth feel and in vivo disintegration time of the control formulation was not determined. The optimized formulation (F28) was found to be pleasant taste with good mouth feel without any grittiness and rapidly disintegrated in oral cavity in

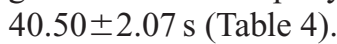

Stability Study The stability results demonstrated that there was no significant change in appearance of the tablets, weight variation, thickness, hardness, friability, water content and disintegration time (Table 5). The results of disintegration time after 6 months of storage were within the USFDA limits $(<60 \mathrm{~s})$ for ODTs. No significant loss was found in the drug content at the end of 6 months. The in vitro release profiles of optimized formulation (F28) stored for $0,1,3$ and 6 months are shown in Fig. 3. There was no significant difference in $\mathrm{DE}_{15 \text { min }}$ values of fresh and stored samples and thus, the formulation F28 was proven to be stable for at least 6 months.

In Vivo Study The mean sumatriptan plasma concentration versus time profiles of reference and test formulation are

Table 4. Evaluation of Taste, Mouth Feel and in Vivo Disintegration Time of Sumatriptan Succinate ODTs Using Human Volunteers

\begin{tabular}{|c|c|c|c|c|c|c|}
\hline \multirow[t]{2}{*}{ Volunteers } & \multicolumn{2}{|c|}{ Taste } & \multicolumn{2}{|c|}{ Mouth feel } & \multicolumn{2}{|c|}{$\begin{array}{c}\text { In vivo } \\
\text { disintegration } \\
\text { time (s) }\end{array}$} \\
\hline & Control & F28 & Control & F28 & Control & F28 \\
\hline 1 & 5 & 1 & - & 1 & - & 40 \\
\hline 2 & 5 & 1 & - & 1 & - & 45 \\
\hline 3 & 5 & 3 & - & 1 & - & 38 \\
\hline 4 & 5 & 1 & - & 2 & - & 39 \\
\hline 5 & 5 & 1 & - & 1 & - & 40 \\
\hline 6 & 5 & 1 & - & 1 & - & 39 \\
\hline 7 & 5 & 1 & - & 1 & - & 41 \\
\hline 8 & 5 & 1 & - & 1 & - & 38 \\
\hline 9 & 5 & 1 & - & 1 & - & 42 \\
\hline 10 & 5 & 3 & - & 1 & - & 40 \\
\hline 11 & 5 & 1 & - & 1 & - & 43 \\
\hline 12 & 5 & 1 & - & 1 & - & 41 \\
\hline Mean & - & - & - & - & - & 40.50 \\
\hline S.D. & - & - & - & - & - & 2.07 \\
\hline
\end{tabular}

$n=12$. Taste: 1 , sweet and good; 2 , tasteless; 3 , slightly bitter; 4 , bitter; 5 , awful Mouth feel: 1 , good; 2 , no feeling; 3 , slight grittiness; 4 , moderate grittiness; 5 , high grittiness. depicted in Fig. 4. The plasma profile of each rabbit showed was highly variable with some of them displayed double peaks or multiple peaks. The results are in line with the findings reported by other researchers. ${ }^{31-34)}$ The possible reason for the appearance of double peaks in many rabbits could be to the presence of two compartment absorption phases with only one disposition phase. ${ }^{35,36)}$ The probable

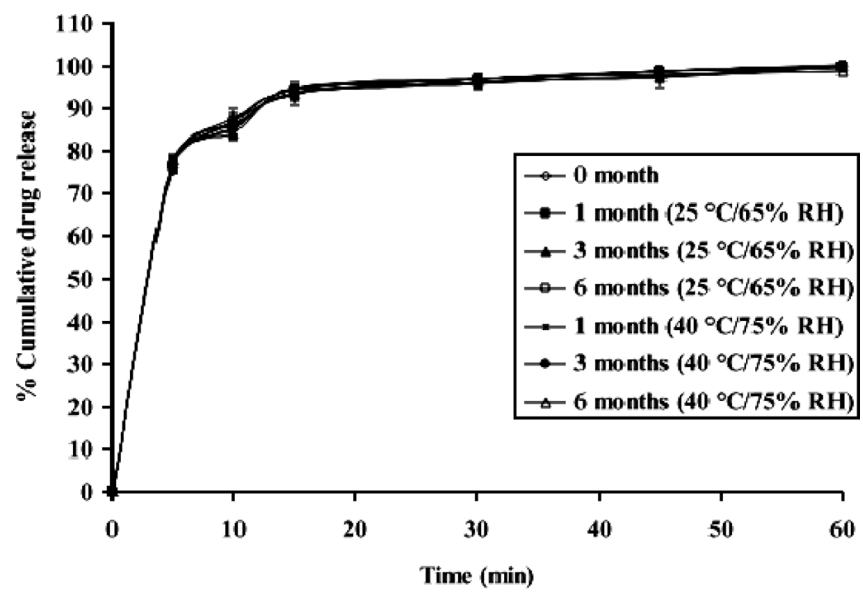

Fig. 3. In Vitro Release Profiles of Optimized Formulation F28 after 1, 3 and 6 Months Storage at Different Temperatures and Humidities

Mean \pm S.D., $n=6$.

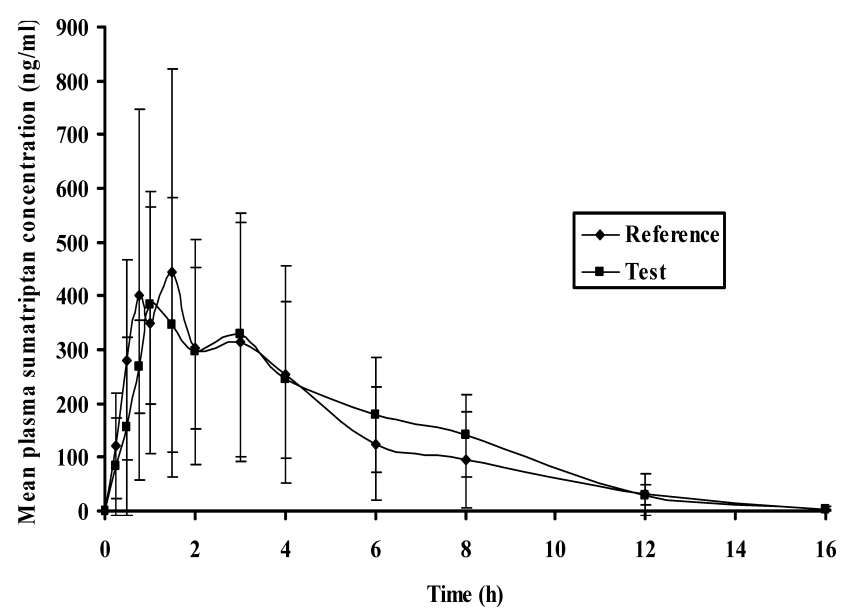

Fig. 4. Mean Plasma Sumatriptan Concentration Profiles after Oral Administration of Reference Product (Suminat ${ }^{\mathbb{B}}$ ) and Test Formulation (F28) in Rabbits

Mean \pm S.D., $n=6$

Table 5. Stability Study Results of Optimized Formulation (F28) after 1, 3 and 6 Months Storage at Different Temperatures and Humidities

\begin{tabular}{|c|c|c|c|c|c|c|c|c|}
\hline \multirow{2}{*}{ Tablet properties } & \multirow{2}{*}{$n$} & \multicolumn{4}{|c|}{$25^{\circ} \mathrm{C} / 65 \% \mathrm{RH}$} & \multicolumn{3}{|c|}{$40^{\circ} \mathrm{C} / 75 \% \mathrm{RH}$} \\
\hline & & 0 month & 1 month & 3 months & 6 months & 1 month & 3 months & 6 months \\
\hline Weight variation (mg) & 20 & $319.56 \pm 1.22$ & $320.22 \pm 1.24$ & $320.76 \pm 0.53$ & $321.31 \pm 0.69$ & $320.93 \pm 0.50$ & $321.47 \pm 1.10$ & $321.50 \pm 1.48$ \\
\hline Thickness (mm) & 10 & $6.42 \pm 0.03$ & $6.43 \pm 0.02$ & $6.43 \pm 0.03$ & $6.45 \pm 0.02$ & $6.41 \pm 0.01$ & $6.44 \pm 0.03$ & $6.45 \pm 0.02$ \\
\hline Hardness (kg) & 10 & $2.54 \pm 0.05$ & $2.56 \pm 0.06$ & $2.51 \pm 0.08$ & $2.51 \pm 0.09$ & $2.52 \pm 0.07$ & $2.49 \pm 0.06$ & $2.48 \pm 0.04$ \\
\hline Friability $(\%)$ & 20 & 0.40 & 0.37 & 0.41 & 0.39 & 0.40 & 0.43 & 0.45 \\
\hline Drug content $(\%)$ & 3 & $100.86 \pm 0.70$ & $100.77 \pm 1.40$ & $100.12 \pm 0.98$ & $99.83 \pm 0.93$ & $100.59 \pm 1.20$ & $99.92 \pm 1.13$ & $99.01 \pm 0.85$ \\
\hline In vitro $\mathrm{DT}(\mathrm{s})$ & 6 & $38.83 \pm 1.47$ & $38.33 \pm 1.63$ & $37.67 \pm 1.86$ & $37.50 \pm 1.38$ & $38.00 \pm 1.41$ & $37.17 \pm 1.17$ & $36.67 \pm 1.63$ \\
\hline Water content $(\%)$ & 3 & $6.40 \pm 0.05$ & $6.42 \pm 0.06$ & $6.48 \pm 0.04$ & $6.52 \pm 0.07$ & $6.45 \pm 0.06$ & $6.51 \pm 0.08$ & $6.54 \pm 0.05$ \\
\hline Dissolution efficiency (\%) & 6 & $69.92 \pm 1.03$ & $69.60 \pm 1.21$ & $70.17 \pm 1.74$ & $69.98 \pm 1.32$ & $70.76 \pm 0.99$ & $69.63 \pm 0.82$ & $69.85 \pm 0.77$ \\
\hline
\end{tabular}

Mean \pm S.D. 
reasons for multiple peaks may be due to alteration in the gastric motility by sumatriptan ${ }^{37,38)}$ and/or presence of multiple absorption sites for sumatriptan in the gastrointestinal tract of rabbits. ${ }^{39)}$ The data demonstrated that plasma concentrations of sumatriptan increased rapidly then fluctuated and reached maximum in all the rabbits at approximately 0.5 to $3 \mathrm{~h}$ for both preparations, thereafter declined gradually over a period of $16 \mathrm{~h}$. The pharmacokinetic parameters, $C_{\max }, T_{\max }$ and $A U C_{0-16 \mathrm{~h}}$ values were $523.32 \pm 346.17 \mathrm{ng} / \mathrm{ml}, 1.42 \pm 0.96$ $\mathrm{h}$ and $2135.87 \pm 1515.89 \mathrm{ng} \cdot \mathrm{h} / \mathrm{ml}$, respectively for Reference and $510.00 \pm 222.57 \mathrm{ng} / \mathrm{ml}, \quad 1.54 \pm 0.84 \mathrm{~h}$ and 2227.44士 $1204.11 \mathrm{ng} \cdot \mathrm{h} / \mathrm{ml}$, respectively for Test formulation (F28). There was no significant difference between pharmacokinetic parameters values of Reference product and Test formulation (F28). Thus, both preparations were bioequivalent in their rate and extent of absorption.

\section{Conclusion}

The taste masked orally disintegrating tablets of sumatriptan succinate containing Kollidon CL-SF (5\%) as a superdisintegrant and ammonium bicarbonate $(10 \%)$ as a subliming agent was successfully prepared using direct compression method followed by sublimation technique. The optimized formulation (F28) had sweet taste, smooth mouth feel and rapidly disintegrated in the mouth within $41 \mathrm{~s}$ and also had good stability. Formulated ODTs showed similar in vitro release profiles with that of a commercial product and also bioequivalent in their rate and extent of absorption. Hence, this "patient-friendly dosage form" could be a useful alternative to commercially available conventional tablets.

Acknowledgements The authors would like to thank Universiti Sains Malaysia for providing research grant to support this work. The author (Ravi Sheshala) gratefully acknowledges Universiti Sains Malaysia, Penang, Malaysia for the granting of a Fellowship.

\section{References}

1) Milton K. A., Scott N. R., Allen M. J., Abel S., Jenkins V. C., James G. C., Rance D. J., Eve M. D., J. Clin. Pharmacol., 42, 528-539 (2002).

2) Graves B. W., J. Midwifery Womens Health, 51, 174-184 (2006).

3) Dixon C. M., Saynor D. A., Andrew P. D., Oxford J., Bradbury A., Tarbit M. H., Drug Metab. Dispos., 21, 761-769 (1993).

4) Yang Z. Y., Le Y., Hu T. T., Shen Z., Chen J. F., Yun J., Pharm. Res., 25, 2012-2018 (2008)

5) Mahajan H. S., Kuchekar B. S., Badhan A. C., Indian J. Pharm. Sci., 66, 238-240 (2004).

6) Shukla D., Chakraborty S., Singh S., Mishra B., Chem. Pharm. Bull., 57, 337-345 (2009).

7) USP XXX, US Pharmacopeial Convention, Rockville, MD, 2007.

8) Ravi S., Darwis Y., Khan N., Acta Chromatogr., 21, $421-432$ (2009).

9) Ishikawa T., Watanabe Y., Utoguchi N., Matsumoto M., Chem. Pharm. Bull., 47, 1451-1454 (1999).

10) Wagner J. G., "Fundamentals of Clinical Pharmacokinetics," 1st ed., Drug Intelligence Publications, Hamilton, 1975.
11) Xu J., Bovet L. L., Zhao K., Int. J. Pharm., 359, 63-69 (2008).

12) DrugBank, 〈http://www.drugbank.ca/drugs/DB00669 $\rangle$, cited 4 November 2009.

13) Late S. G., Yu Y. Y., Banga A. K., Int. J. Pharm., 365, 4-11 (2009).

14) Patel D. M., Patel M. M., Indian J. Pharm. Sci., 70, $71-76$ (2008).

15) Singh R., Madan J., Drug Inv. Today, 1, 146-149 (2009).

16) Shinde A. J., Waghule A. N., Amol P., More H. N., Res. J. Pharm. Biol. Chem. Sci., 1, 46-50 (2010).

17) Kumar R., Patil M. B., Patil S. R., Paschapur M. S., Int. J. Pharm. Pharm. Sci., 1, 65-73 (2009).

18) Jeevanandham S., Dachinamoorthi D., Chandrasekhar K. B., Muthukumaran M., Sriram N., Joysaruby J., Asian J. Pharm., 4, 48$51(2010)$

19) Gelone S., Gennaro A. R., "Remington: The Science and Practice of Pharmacy," ed. by Troy D. B., Lippincott Williams and Willkins, Baltimore, 2006.

20) Tekade N. P., Bhajipale N. S., Ganesan V., Thenge R. R., Dewade D. R., Int. J. ChemTech Res., 2, 400- 405 (2010).

21) Khemariya P., Gajbhiye K. R., Vaidya V. D., Jadon R. S., Mishra S., Shukla A., Bhargava M., Singhai S. K., Goswami S., Int. J. Drug Deliv., 2, 76-80 (2010).

22) Battu S. K., Repka M. A., Majumdar S., Madhusudan R. Y., Drug Dev. Ind. Pharm., 33, 1225-1232 (2007).

23) He X., Kibbe A. H., "Handbook of Pharmaceutical Excipients," ed. by Rowe R. C., Sheskey P. J., Weller P. J., Pharmaceutical Press, Washington, 2003.

24) Setty C. M., Prasad D. V. K., Gupta V. R. M., Sa B., Indian J. Pharm. Sci., 70, 180-185 (2008).

25) Swamy P. V., Areefulla S. H., Shirsand S. B., Gandra S., Prasanth B., Indian J. Pharm. Sci., 69, 836-840 (2007).

26) Khan S., Kataria P., Nakhat P., Yeole P., AAPS PharmSciTech, 8, E1E7 (2007).

27) Patel D. M., Patel N. M., Shah R. R., Jogani P. L., Balapatel A. I., Indian J. Pharm. Sci., 66, 621-625 (2004).

28) Mishra D. N., Bindal M., Singh S. K., Vijaya Kumar S. G., Chem. Pharm. Bull., 54, 99-102 (2006).

29) Bi Y., Sunada H., Yonezawa Y., Danjo K., Otsuka A., Iida K., Chem. Pharm. Bull., 44, $2121-2127$ (1996).

30) USFDA, "Inactive Ingredient Search for Approved Drug Products," Food and Drug Administration, Centre for Drug Evaluation and Research (CDER), Rockville, MD, 2009 (http://www.accessdata.fda.gov/ scripts/cder/iig/index.cfm).

31) Lacey L. F., Hussey E. K., Fowler P. A., Eur. J. Clin. Pharmacol., 47, $543-548$ (1995).

32) Dahlöf C. G., Curr. Med. Res. Opin., 17 (Suppl. 1), s35-s45 (2001).

33) Carpay J., Schoenen J., Ahmad F., Kinrade F., Boswell D., Clin. Ther, 26, 214-223 (2004).

34) Ferrari A., Pinetti D., Bertolini A., Coccia C., Sternieri E., Eur. J. Clin. Pharmacol., 64, 489-495 (2008).

35) Fowler P. A., Lacey L. F., Thomas M., Keene O. N., Tanner R. J., Baber N. S., Eur. Neurol., 31, 291-294 (1991).

36) Christensen M. L., Mottern R. K., Jabbour J. T., Fuseau E., J. Clin. Pharmacol., 43, 721-726 (2003).

37) Sifrim D., Holloway R. H., Tack J., Zelter A., Missotten T., Coulie B., Janssens J., Am. J. Gastroenterol., 94, 3158-3164 (1999).

38) Vingerhagen S., Hausken T., Gilja O. H., Berstad A., Neurogastroenterol. Motil., 12, 95-101 (2000).

39) Duléry B. D., Petty M. A., Schoun J., David M., Huebert N. D., J. Pharm. Biomed. Anal., 15, 1009-1020 (1997). 